\title{
Evaluating SMEs Growth Strategies: The Case Study of A Medium-sized UK Specialty Chemical Distributor
}

\author{
Hendrik Frentzen \\ School of Strategy, PR and Communications, Leeds Beckett University, United Kingdom \\ E-mail: hfrentzen@obe.com
}

Evripidis Lampadarios (Corresponding Author)

School of Strategy, PR and Communications, Leeds Beckett University, United Kingdom

E-mail: e.lampadarios@leedsbeckett.ac.uk

Received: Aug. 25, 2016 Accepted: Sept. 20, $2016 \quad$ Published: Sept. 27, 2016

doi:10.5296/csbm.v3i2.9944 URL: http://dx.doi.org/10.5296/csbm.v3i2.9944

\begin{abstract}
The UK chemical distribution industry, a well-established, highly fragmented, subject to strong consolidation and significant part of the chemical industry, is a major contributor to the UK economy and employment. The ever increasing regulatory compliance requirements pose a significant challenge to all companies in general but more so to SMEs which have a strong presence in this industry. Even though there has been considerable research in the area of small business growth, best practices for SMEs in the chemical distribution industry are scarce. This is one of the few research papers that address this gap in knowledge in a case study context in the specific industry, arguing that a mix of inorganic and organic growth is the best way to achieve growth. Findings suggest that the strategy depends on the vision of the owner/manager, strategies in place, access to human resources and finance, past experiences, industry characteristics and company structure. Despite the methodological limitations of this study, this can be used as the basis for future research and to inform key stakeholders and policy makers.
\end{abstract}

Keywords: Growth Strategies, SMEs, UK Chemical Distribution Industry, Case Study 


\section{Introduction}

Small and medium-sized enterprises (SMEs) play a crucial role in the economy, "driving economic growth by stimulating innovation, acting as a competitive spur to existing businesses and making a disproportionately large contribution to job creation" (BIS, 2014). In the UK specifically, SMEs account for $99.3 \%$ all businesses in every main industry sector (CIA, 2015). With a combined annual turnover of $£ 1.8$ trillion and employing 15.6 million people in 2015, they represent $60.3 \%$ of UK workforce (FSB, 2015). The UK government is aware of the importance of SMEs and actively supports their development through "business support, improved access to finance, fewer barriers to market entry and by creating a more entrepreneurial culture" (BIS, 2014, p. 9). Growth, in means of turnover and/or profit, is imperative for small business survival in such a fierce business environment and only the ones these are able to create a sustainable competitive advantage in their industry will be successful in the long term (Lampadarios, 2016a and c; Papulova et al., 2006).

An industry where small businesses have a particularly strong presence is the European and especially the UK chemical distribution (Districonsult, 2013; European Association of Chemical Distributors [FECC], 2013). However, very little is known about SMEs in the specific industry, their modus operandi and subsequent growth strategies (Chemical Business Association [CBA], 2015; FECC, 2015). In fact, due to the wide variety of functions performed by these companies and confusion with other types of trading in the industry, there is still no universally agreed definition of a chemical distributor (Chemagility, 2012).

Even though there has been considerable research (OECD, 2002; Pasanen, 2007; Goldman, 2014; Lee, 2014) in the area of SME growth, the UK chemical distribution industry and the characteristics of SMEs operating in it, is heavily understudied. There is limited research available on an academic as well as a professional level. Therefore, conducting a case study with a UK chemical distributor is of major importance and provides a good basis for further empirical research in this area. To that end, this study evaluates the different growth strategies of a UK Small medium-sized specialty chemicals distributor. The aim of this study is threefold: to analyse the different available growth strategies, to evaluate the current strategy and to identify the most suitable growth strategy for the company's future.

\section{Small and Medium-sized Enterprises (SMEs)}

Even though SMEs is an area well researched, there is still no universally accepted definition of what constitutes a small business with variations existing in different countries. In the United Kingdom, the definition of SMEs is given through the UK Companies Act of 2006 which states that if a company is to be defined as "small", it must satisfy at least two of the following criteria: (i) have a turnover of no more than $£ 6.5 \mathrm{~m}$; (ii) have a balance sheet total of no more than $£ 3.26 \mathrm{~m}$; (iii) have no more than 50 employees. Similarly, a medium-sized company must satisfy at least two of the following criteria: (i) have a turnover of no more than $£ 25.9 \mathrm{~m}$; (ii) have a balance sheet total of no more than $£ 12.9 \mathrm{~m}$; (iii) have no more than 250 employees.

In the European Union, any enterprise that employs fewer than 250 persons and has an annual 
turnover not exceeding EUR 50m and/or an annual balance sheet total not exceeding EUR $43 \mathrm{~m}$ qualifies as a SME (European Union, 2015). Within the SME category, a small enterprise is defined as an enterprise which employs fewer than 50 staff and whose annual turnover and/or annual balance sheet total does not exceed EUR 10m while a microenterprise is defined as an enterprise which employs fewer than 10 persons and whose annual turnover and/or annual balance sheet total does not exceed EUR $2 \mathrm{~m}$. For the purpose of this study, the definition of SMEs is that of the European Union.

\subsection{Growth and Strategic Planning}

In general, growth "refers to an increase in the firm's turnover ... [or] change in the number of employees" (Pasanen, 2007, p. 320). However, there is a clear distinction made between organic growth and inorganic growth (often referred to as acquisition growth) with each type having its own advantages and disadvantages and each with a different effect upon the performance of the firm (Delmar et al., 2003). Both ideally lead to an increase in margins / profit for the company (BIS, 2014). Notably, Smallbone et al. (1995) argues that due to the various types of SMEs and the range of factors affecting growth there is no theory that can adequately explain SME growth. Even though the theoretical understanding has improved due to the implementation of definitions by the European Commission in 2005, empirical understanding is still unclear. This might be because of the variety in types and the different variables, which affect small business growth (Farouk et al., 2011).

According to Pasanen (2007) growth is essential in small businesses as it ensures an adequate production volume, increases profitability by enlarging a firm's market share, secures the continuity of business, leads to new business opportunities and enhances the credibility in the market due to the larger size. This is in line with McKaskill (2010), who argues that larger businesses have greater resilience, specialisation and command higher margins. Even though most SMEs are aware of the importance and benefits of growth, some appear to be more successful than others. Wang et al. (2007, p. 3) point out that "a key determinant of business success lies in the absence or presence of strategic planning". In this context, strategic planning "translates" into setting long-term goals, developing and implementing plans to achieve these goals and allocating the right resources to realize them. In fact, SMEs that use strategic planning are more likely to be better performers compared to those who do not (Gibson \& Cassar, 2005).

To date, it is still unclear why some SMEs do strategic planning and others don't (O'Regan, 2002, cited in Wang et al., 2007, p. 3). According to Robinson \& Pearce (1984) planning occurs more reactive rather than proactive among SMEs. Furthermore, the four most common reasons identified for not using strategic planning are lack of time, lack of knowledge, lack of expertise and lack of trust and openness.

\subsection{Growth Strategies for SMEs}

In general, the literature about SME growth strategies discusses organic as well as inorganic growth. Whereas some scholars point out the importance of partnerships and strategic alliances for SMEs (OECD, 2002; Hoffmann et al., 2001), Salvato et al. (2007) claim that 
inorganic growth is not very popular and most entrepreneurship growth has been addressed to organic growth. However, Salvato et al. (2007) stress that in the long-term, inorganic growth may have more entrepreneurial benefits. In contrast, Pasanen (2007) and Delmar et al. (2003) argue that the growth pattern of SMEs changes by firm characteristics such as age, size and industry.

\subsubsection{Organic Growth}

Organic growth is one out of two strategic options managers need to address (Penrose, 1959). According to Lockett et al. (2011, p. 52), organic growth "involves the internal generation of resources, e.g., by employing and training new staff'. This form of growth is associated with low up-front costs and therefore it is especially of interest to small businesses that want to expand their business but don't have the capital requirements to do so. Organic growth can increase your market share and improve customer retention but it is considerably slower and it might well be that the marketplace will not let the SME grow beyond a certain point (Mack, 2015). This is when inorganic growth becomes crucial. There are different ways for companies to grow organically as for instance entering new industries, offering new products and services, expanding the customer base or restructure the overall business model (Fullsurge, 2013).

\subsubsection{Inorganic Growth}

This kind of strategy can be an attractive alternative for SMEs, especially when many resources are non-standard, complex, involve tacit knowledge and are firm specific. In general, inorganic growth means that "one firm buys controlling interest in another firm and the acquired business is integrated within current operations or becomes a subsidiary of the acquirer's portfolio" (Lockett et al., 2011, p. 52). This form of growth has numerous advantages for SMEs such as reducing competition in the market, increasing the product portfolio of the company, providing access to new customers and leading to a "fresh breath of the management" (Hyland et al., 2013, p. 9). This approach is generally considered less risky and more time effective (McKaskill, 2010). On the other hand, acquiring a new business or new capabilities can be highly problematic to an existing business, if the resources and skills required to take on an acquisition are not there. Moreover, acquisitions should be in line with the overall business strategy, rather than just "opportunistic buying" (McKaskill, 2010, p. 10). The three most popular forms to grow inorganically are through mergers, acquisitions or strategic alliances (Hyland et al., 2013).

Although Mergers and Acquisitions (M\&A) are terms used interchangeably, their definitions are slightly different. In the pure sense of the term, a merger is the "combination of two or more companies in creation of a new entity or formation of a holding company" (Hoang et al., 2007). Mergers differ depending on, for example, the strategic rationale behind the deal, if they are friendly or hostile, domestic or cross-border, or even on the degree of integration (Faulkner et al., 2012). In contrast, in an acquisition a company buys shares in another company to achieve a managerial influence. An acquisition may be of a minority or of a majority of the shares in the acquired company (ECB, 2000). This purchase can be completed with cash, stock or the combination of both. Furthermore, an asset deal is also possible. 


\section{Macrothink Institute ${ }^{\mathrm{TM}}$}

Whether a purchase is considered a merger or an acquisition depends on whether the purchase is friendly or hostile and how it is negotiated. In an acquisition, a negotiation process does not necessarily take place (Roberts et al., 2012). In general, the purpose of mergers and acquisitions is the same, characterised by maximizing synergy effects to benefit from cost reductions, economies of scale, new markets and new technologies. However, this is easier said than done-between 50 and 85 percent of mergers and acquisitions fail (Heffernan, 2012). According to McKaskill (2010), there are four areas where problems occur in an acquisition: in the acquired business, in the integration process, in miscalculation of anticipated benefits and external unforeseen circumstances. Johnston (2015) states that mergers and acquisitions, for small businesses, can be a suitable alternative to organic growth. However, these need to make sure that they have the right resources in place and are able to expand their management capabilities appropriately.

Overall, there are several reasons for companies to acquire a new company. According to Caiazza \& Volpe (2015) companies want to increase their market power, achieve economies of scale and scope or cost advantages through vertical integration, which will lead to an enhanced competitive advantage of both companies. Risberg (2006) argues that there are two main types of motives for M\&A: (i) financial reasons (increasing overall performance, creating shareholder value) and (ii) non-value-maximizing managerially based motives. Other scholars, such as Brouthers et al. (1998) distinguish between economic, personal and strategic motives.

Another form of inorganic growth is strategic alliances, which are defined as "two organisations opting to cooperate for a certain period of time with regard to specified joint objectives..." (Faulkner et al., 2012, p. 689). Figure 1 summarises the different types of Strategic Alliances by level of interaction and type of arrangement. In fact, there are various drivers for creating strategic alliances, with Elmuti et al. (2001) illustrating growth strategies and entering new markets; to obtain new technology and/or best quality or cheapest cost; to reduce financial risk and share $\mathrm{R} \& \mathrm{D}$ costs; and to achieve or ensure competitive advantage. In contrast, Todeva et al. (2005) points out 18 motives to enter a strategic alliance, which include Elmuti's findings and others, such as overcoming legal/regulatory barriers and achieve vertical integration. 


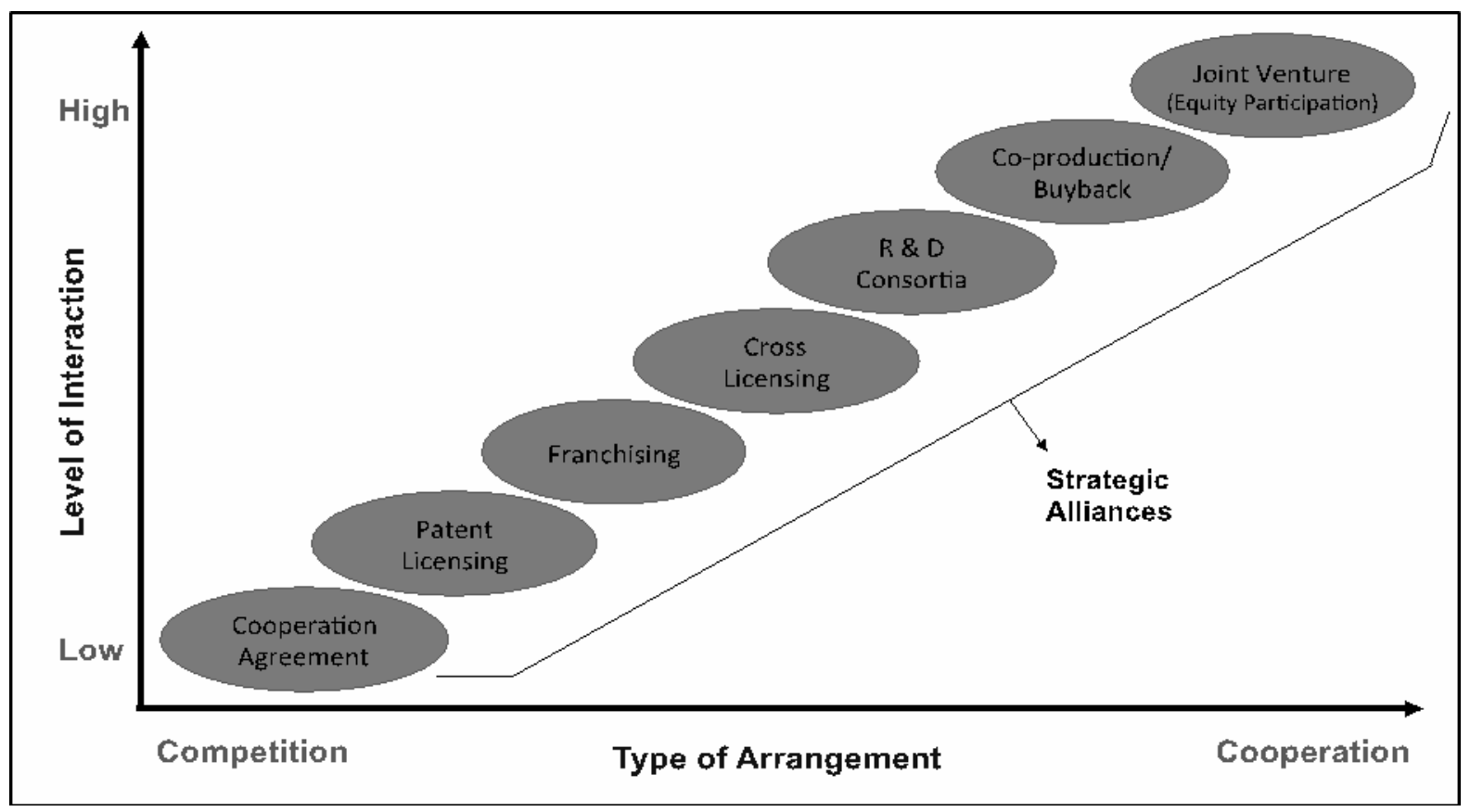

Figure 1. Different types of Strategic Alliances by level of interaction and type of arrangement

As with all other forms of inorganic growth, this type is also associated with some risks, such as clash of cultures and incompatible personal chemistry, lack of trust, lack of clear goals and objectives or lack of coordination between management teams (Elmuti et al., 2001). Although most of the companies seem to be aware of the risks, over $60 \%$ of strategic alliances fail (Kalmbach et al., 1999). This leads to the question of establishing when strategic alliances should be chosen. Brouthers et al. (1995) argue that strategic alliances should only be utilised when the partners offer complementary skills; cooperative cultures exist between the firms; the firms have compatible goals; and commensurate levels of risk are involved. This kind of analysis is called the four Cs of strategic alliances (Brouthers et al., 1995). According to Swoboda et al. (2011, p. 272), international SME alliance success depends on the strategic, structural and cultural fit of the partner. However, partner selection and negotiation problems can have a negative influence on the alliance. As a result of his study, Swoboda et al. (2011, p. 283) indicate that "the degree of an international SME alliance success depends primarily on the levels of structural and cultural fit between alliance partners, and that strategic fit is less important."

\section{The UK Chemical Distribution Industry}

The chemical distribution industry is a well-established, highly fragmented industry with more than 10,000 distributors worldwide and about 240 distributors in the UK (Jung, 2010; Chemagility, 2008). The five biggest distribution companies worldwide (Brenntag, Univar, Ashland, Ravago, \& Helm) controlled less than 19 percent of the chemical distribution market in 2008 (Jung, 2010). The global chemical distribution market is expected to continue to grow in the coming years. According to a report by the Boston Consulting Group (2014) 
the compound annual growth rate between 2008 and 2013 was $6.5 \%$ with a market size of $€ 168$ billion in 2013. The UK chemical distribution industry is an important part of the chemical industry and a major contributor to the overall UK economy and employment. According to a survey within the global chemical distribution industry conducted by the Boston Consulting Group, one of the key criteria for customers to choose a chemical distributor is technical support, application expertise, customer tailored service and regulatory support (REACH) (Jung, 2012). Chemical distributors offer various services to their suppliers and their customers. Services for suppliers include demand forecasting and planning, repackaging and relabelling, new product approvals and arrangement of import authorizations. On the other hand, services to customers include access to reputable suppliers, competitive and stable pricing, product expertise and technical support (Lampadarios, 2016a). Figure 2 summarizes the important role of a European chemical distributor as well as the main requirements and success factors identified by Falter (2015).

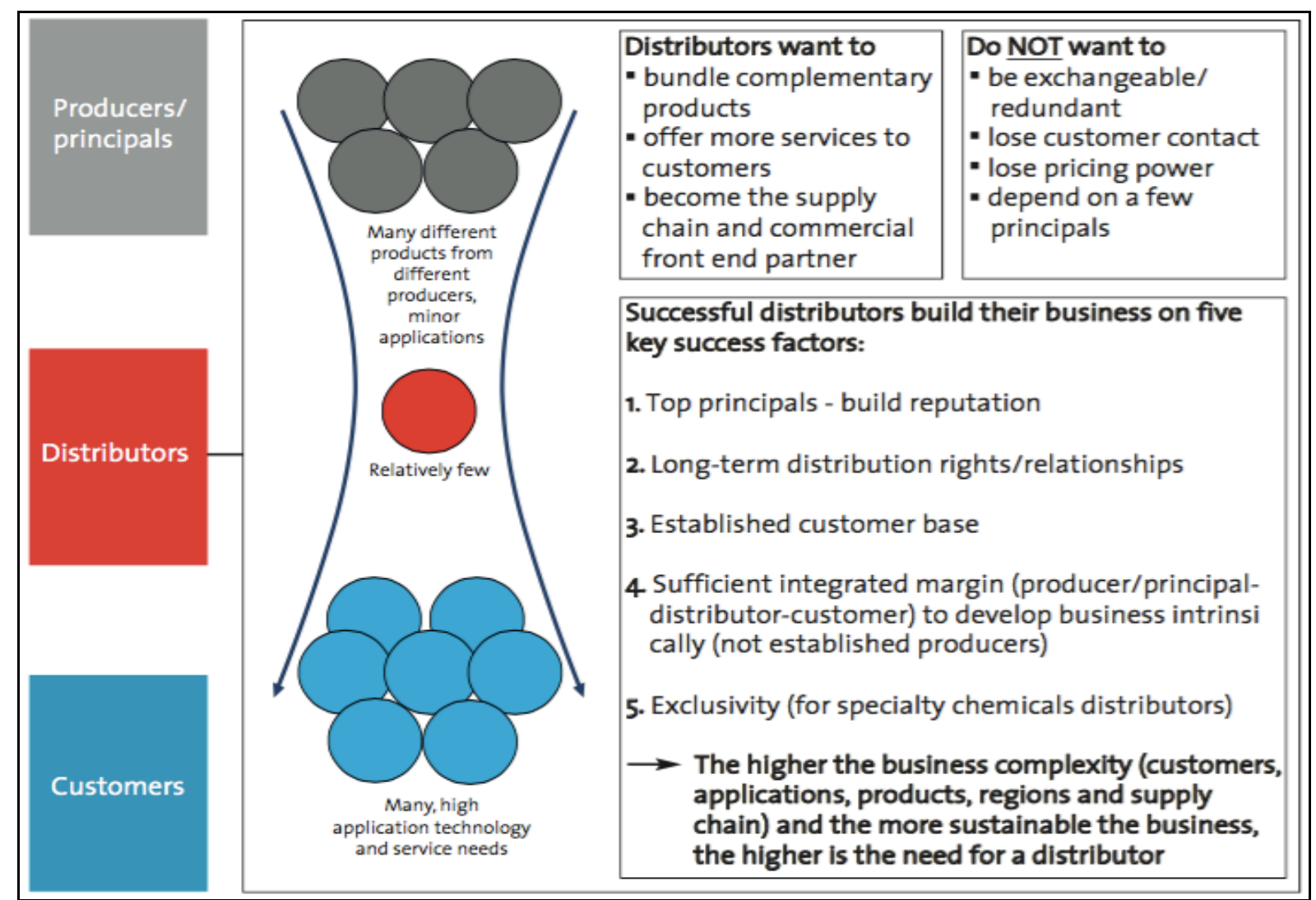

Figure 2. Chemical distributor's overview (Falter, 2015)

On investigation of the most common practice in the chemical distribution industry, inorganic growth, and in particular mergers and acquisitions, seem to be the most popular growth strategy for bigger chemical distributors (Chapman et al., 1998; Fermont, 2007; Districonsult, 2012; Mortelmans et al., 2012; Chang \& Beacham, 2014; Walberer, 2014; Young, 2014). According to Chang \& Beacham $(2014$, p. 1), many distributors plan to be active in M\&A as 
the "fragmented chemical distribution sector needs to consolidate to keep up with customer needs". Furthermore, "quite a number of medium-sized, privately owned distributors have identified acquisitions as a key part of their growth strategy ... they have realised that you need a certain geographic reach to be successful" (Chemweek, 2012, p. 25).

In a study about the Chemical Distribution Industry, Hornke (2012, p. 18) identifies four primary reasons for M\&A, which included increase of market share in existing markets; expansion to new geographical markets; expansion to new product markets and increase in efficiencies and economies of scale. Especially in the specialties and fine chemicals market $64 \%$ of the respondents of a survey conducted by Kearney (2014) saw the M\&A development for 2014 increasing. In contrast, Walberer (2014, p. 3) argues that "a final trend that is expected to continue in 2014 is the increase in alliances and partnerships between companies when pursuing larger deals and investments". He supports this statement by providing an example about many SMEs who are interested in low-cost US feedstock, but cannot "tap into the opportunity on their own". Walberer (2014) also highlights that these companies are looking for partners to minimise the risk of an investment or an acquisition but also to acquire additional funds and capabilities.

\subsection{Critical Success Factors for SMEs in the UK Chemical Distribution Industry}

As mentioned earlier the research about SMEs in the UK chemical distribution industry is scarce. The only study published in this specific industry is the one by Lampadarios (2016b) who investigated the critical success factors of SMEs in the UK chemical distribution industry. In doing so, Lampadarios" argues that "success is a multidimensional phenomenon where both firm-internal and firm-external factors need to be optimal simultaneously; satisfying one or two factors does not necessarily guarantee success" (Lampadarios, 2016b, p. 67). After an extensive study with 118 SMEs from the UK chemical distribution industry, out of the 180 identified, Regulatory Compliance, Entrepreneurial Orientation, Customer Relations Management, Market and Product Development, Prior Work Experience and Management Skills, Human Capital, Economic Environment and Strategic Planning as critical success factors.

Overall, the findings are in line with general small business literature (Jung, 2010; Jung et al., 2014; Falter, 2015). SME success is dependent on several factors which need to work simultaneously in order the business to become successful. A research carried out on a broader scale was the study by Jung et al. (2014), looking at the global speciality chemical distribution industry. According to Jung et al. (2014) being globally successful requires seven success factors: (i)strong expertise; (ii) the right product portfolio; (iii) strong access to local clients; (iv) close collaboration with suppliers; (v) support pan-regional supplier relationships; (vi) process quality and IT excellence, and (vii) a combination of organic and inorganic growth.

\section{Methodology}

This study follows a phenomenological research philosophy, is deductive in its approach and uses a single case study research strategy. Qualitative data was collected through face-to-face, 
semi-structured interviews with three business managers, a technical manager and the Managing Director. Hence, valuable and in-depth information about the company, its strategy and industry have been gathered. Deductive qualitative content analysis was used to investigate the primary data. The overall aim of this study is to evaluate the different growth strategies of a UK small medium-sized speciality chemicals distributor.

Construct validity is achieved through the use of a wide range of primary and secondary data. The design of the interview questions is based on the knowledge gained from theory of the literature. Internal validity is achieved through the use of a clearly defined data analysis method. External validity tests the ability for generalisation. As a result of using only a single case study within the chemical distribution industry, findings of this study cannot be generalised. This criterion "represents the most significant weakness of a case-based research programme" (Schell, 1992, p. 13). However, the findings offer a good basis for future research.

Reliability is accomplished through semi-structured interviews. The fact that the researcher was the only person asking the questions increased reliability. The findings are not "necessarily intended to be repeatable since they reflect reality at the time they were collected, in a situation which may be subject to change" (Marshall \& Rossman, 2006 cited in Saunders et al., 2012b). The questions were based on the knowledge gained from secondary data. According to Schell (1992, p. 13), reliability is "most important during the data collection phase, and involves the use of case study protocol as well as the case study database...".

\section{Case Study: Growth Strategy of a UK Specialty Chemical Distributor}

The company used for this research project is a typical example of a small medium sized enterprise from the UK. Originally founded in the late 18th century, the company is now one of the leading UK based global distributor of specialty chemicals. Furthermore, the company is part of a bigger group, which has helped them to diversify in many markets and expand their product portfolio. The company currently employs 14 individuals and focuses on the distribution of speciality chemicals in the UK and the rest of the world. Strong relationships with suppliers and first class key partners throughout the EU, Southeast Asia and the US are very important. Until the time of the study, the company had grown organically, through acquisitions and by developing a network of distributors. This has helped to increase the product portfolio, but also to expand the operations on a worldwide basis. Today, the company has key agents/distributors in many countries, such as Belgium, Brazil, Germany, Greece, Netherlands, Turkey, Spain, Portugal and South Africa. The company aims to deliver first class chemical products worldwide to customers in all industry sectors, to provide strong technical and legislative support, to understand the customers" needs and to source products from market leading suppliers with the best product quality available.

\section{Findings and Discussion}

In order to achieve the aim of the study, it is necessary to understand the industry the company operates in. This is in line with Porter (1980), who argues that the industry structure has a big impact on the strategy and the competitive situation of the company. Hence, the 
participants were asked to illustrate the main characteristics and success factors of the chemical distribution industry, as well as to evaluate whether it is a high growth industry and if there is a need to grow.

Regarding the main characteristics and success factors of the chemical distribution industry, the participants came up with slightly different opinions. For example, for one interviewee (R1) quality, technical know-how, service and strategic partners are the main characteristics and success factors of the industry. In contrast, another interviewee (R2) argues: "If you are a chemical distributor you need to have good principals (...) either have good principals or unique products that are only available for yourself or a few distributors". He further states "it is important for SMEs to be more specialized, so that they can offer a benefit to their principals."

Another interviewee (R5) clearly differentiates between characteristics and success factors and points out the characteristics of the industry by saying: "It is very well established and it is a mature market. The idea of a chemical distributor has been long established. So there has always been a "need for a middleman". (...) There is also a lot of consolidation and a clear cut between very large and small distributors (...) It is the 80:20 rule (...) 20\% of the large distributors have $80 \%$ of the market... and obviously the other way round".

Furthermore, the participant has a clear idea about the success factors of a chemical distributor: "The top one is regulatory compliance. So you have to comply with the regulation, because if you don't, you are actually excluded from the market (...) Customer Management is extremely important. You have to look after your customers, maintain the ones you have and grow the other ones as well (...) Human Resources are very important, especially at the time of all these regulations. You need to bring more expertise into your business (...) Finance is very important, because you don't want to run out of steam".

In contrast to the more detailed statements before, another participant (R4) kept his comments very brief by saying that "(...) you need to have good suppliers, good prices and a good supply chain".

If the chemical distributor has a good supply chain, and more importantly, is able to control it, the company will be successful. Additionally, these statements are in line with the earlier mentioned characteristics and success factors of the UK chemical distribution industry in section 4.3 (Jung, 2010; Jung et al., 2014; Falter, 2015; Lampadarios, 2015).

For all of the participants, the chemical distribution industry is not a high growth industry. However, "it is most definitely a growing industry, but what you find is that bigger distributors are getting bigger and they are absorbing a lot of the smaller distributors (R2)". According to Frost (2013) the worldwide chemical distribution industry grew from 2008 to 2012 by $9 \%$ annually. The BCG expects the real growth rate in the global chemical distribution market to slow down from $7 \%$ /year to $6 \%$ /year within the next five years (Frost, 2013). Therefore, the statements of the interviewees can be confirmed by the literature.

Moreover, every respondent thinks that there is a need to grow for the company in the industry. One participant (R2) highlights the importance of growth by saying: "I think it is 
essential to grow in the industry, because if you stay still, you'll get taken out of the equation or you'll be eaten up by one of the big distributors. (...) If we stay as we are, we are very liable for attack". This is in line with the statement of another interviewee (R3) who points out: "it is a must to grow. If you don't grow, you go backwards".

To conclude, main industry characteristics and success factors could be confirmed from the participants. Moreover, it was clear to see that the chemical distribution industry is a growing industry and that there is a need to grow for the companies, especially SMEs, in order to survive in this industry

\subsection{Challenges in the UK Chemical Distribution Industry}

For all of the participants" regulatory compliance and REACH are the biggest challenges in the industry. One participant (R3) explains the regulatory situation by saying: "when I joined the industry in the 70s, the industry was under-regulated. And now I would say it is over-regulated. Almost every month there is a new regulation coming out. It is time and cost-for small companies it is a lost sales time". On top of that, "(...) you have to have people, who actually understand these regulations. It seems over complicated, because of the fact that you need a PhD in Chemistry to actually understand these regulations. Many small companies cannot afford that".

Another interviewee (R1) is a little bit more specific about the consequences of REACH for smaller businesses: "regulations have an huge effect on the growth of the companies (...) Companies could join forces, but the problem is the amount of money that we are talking about for each registration (...) the market for SMEs isn't really big enough to allow you spending these amounts of money (...) If you don't register your product, there is no market to sell and in the end you have to shut down your business". In the end, "Reach will be a problem in the future and will have an effect on all distributors in a similar way".

Due to all these regulations, one participant (R5) argues that there will be strategic challenges for smaller companies in the future: "The strategy is very important as well... now you see more people (owners) who actually start planning. That is also because of REACH as well. There are deadlines for these regulations and you have to start planning in advance”. This can be linked back to Robinson \& Pearce (1984) as mentioned earlier, who argues that strategic planning occurs more reactive rather than proactive among SMEs.

Moreover, regulatory compliance is not the only challenge smaller businesses have to face within the chemical distribution industry. "Overdependence from one major manufacturer is often a big problem for SMEs. Bankruptcy of one big manufacturer or supplier means losing a lot of money and has an effect for our company" (R1). Furthermore, competition against the big distributors in the market, access to finance, consolidation of companies, but also logistics can be a challenge for SMEs according to the interviewees.

"Consolidation is a very big challenge, because you are in the position as a small company, where you either have to buy or you getting incredibly pressured to be bought" (R5). According to Chemagility (2008), it is medium-size regional distributors that are facing increased pressure to be acquired. The same interviewee argues that it is crucial "(...) to have 
the global logistics in place and to rely on other people".

In addition, a different participant (R2) believes, “(...) for us, we are very much UK based, the challenge is making sure that our principals see the benefit in still working with us. But also we need to diversify and we need to make sure that we are not so reliant on one or two principals".

All the above-mentioned challenges are in line with a study carried out by Lampadarios (2016c) specifically in the UK chemical distribution industry. He identified regulatory compliance (drain on human and financial resources), supplier management (maintaining existing and finding new ones), human capital (finding, attracting and maintaining qualified and skilled people) and access to capital as critical challenges for SMEs in the industry.

The answers from the participants are also in line with a UK Chemical Distributor Market Report by Chemagility (2008, p. 4), whereby "Reach was seen as having the biggest negative impact by companies to their future business". It is also mentioned that "Reach" has a negative effect especially on smaller businesses and might force some distributors to exit the market. On top of that, consolidation trends are supposed to continue in Europe and consequently the number of UK distributors is expected to fall in the coming years.

\subsection{Case Study Evaluation}

In order to achieve the aim of the study, the participants were asked to explain the competitive situation, the strategy, the management style and also the past growth pattern of the firm.

\subsubsection{Competitive Situation}

The majority of the participants describe the market as very competitive. This is in line with the earlier stated study of the BCG, which describes the industry as highly fragmented (Jung et al., 2014). "There are a lot of distributors. You've got presence of very few larger distributors (...) you have a lot of SMEs (...) It is a competitive situation in a mature market" (R5). Another participant (R1) describes the situation as follows: "It is very competitive, as there are many distributors who sell the same products as we do. (...) Personal relationships, price and service are the main factors distributors compete with".

Especially smaller distributors are very much reliant on their manufacturers and suppliers, but also minor effects in the economy, can have a big impact: "We are very much reliant on our principals to support us. (...) Due to the low margins in commodity products, a small change for example in the exchange rate can decrease or increase our competitiveness" (R2). In addition, another interviewee (R3) points out why the company is a successful distributor in the UK, "we are competitive because we are aligned with some major producers. With this support we can take over any distributor (...)".

\subsubsection{Current Strategy}

Whereas one participant (R1) thinks that there is no strategy in place, another one believes that "In the end, the strategy is set by the directors. We can only guess. (...) I think we all 
have ideas on where the business is going, but in the end the MD makes the decision" (R2). Furthermore, the strategy is not written down and seems to be not communicated enough across the whole company. As one of the participants (R3) admits, "Yes [there is a strategy in place], as far as the group directors are concerned, but it is probably a weakness, because it is not a written strategy". This is quite common in the business literature, especially in smaller companies. Pleitner (1986, cited in Terziovski, 2007) argues that strategies reduce SMEs flexibility and scope of activities too much. This is why many SMEs are still lacking written strategic plans.

Nevertheless there are two participants (R3, R5), who have a clear view about the company's strategy: "We are trying to do organic growth in the UK and we are trying to work with distributors and through alliances outside the UK. So we have an established network of distributors in the UK, who sell our products. (...) We are actually looking for buying another company. But, we haven't been able to identify one that we can actually buy. Everyone is trying to do the same thing. So it is very competitive". The other participant (R3) supports this statement by saying "organic growth has been slow, particularly because of recession (...) we want to grow inorganically".

According to Varaiya et al. (1987, cited in Kim et al., 2011) this is typical among businesses, "if organic growth is not forthcoming, firms often turn to other growth strategies like acquisitions as they search for alternative means for achieving the level of growth that their stakeholders demand". Even though this statement cannot be linked directly to smaller businesses, it is useful in explaining the current situation of the distributor. As mentioned earlier, the company is part of a group of companies. Several respondents mentioned the fact that inorganic growth is highly encouraged by the group owners.

The management style is described as very informal, relaxed, not regimented and with a lot of responsibilities and autonomy for every employee. The structure of the company is very flat and the atmosphere can be described as very friendly- "It is a very nice company to work for... the MD takes everybody's input and in the end he makes the decision" (R2). One participant (R5) describes the communication style as "(...) very informal. We do tend to talk a lot (...) a very open working area." The management and communication style is an advantage as one respondent (R3) explains: "We are much faster than the big companies for example getting a price for a chemical from a big distributor took almost 4 weeks”.

This is common practice among smaller businesses, as a study by Matlay (1999, cited in Machado, 2013) revealed: 90\% of British SME owners preferred informal management styles. Moreover, "informality is an important aspect of small firm employment relations and culture" (Machado, 2013, p. 150).

\subsubsection{Past Growth Pattern}

The past growth pattern is described as a mix of organic and inorganic growth: "It's been a steady growth. There have been two strategic acquisitions, which put the company on a different footing... in 2000 a company called (...) bought us ... as we were basically bankrupt... and in 2006 [we] bought a small company (...) (R1)." Another participant (R2) 
explains, "(...) obviously, we have got new principals on board, new alliances and agreements, but the old ones are still the key ones." In the past years, many distribution agreements and other forms of strategic alliances have been signed.

The way of actually looking for new partners and strategic alliances is described as very informal "the internet does help quite a lot (R5)" and "(...) more reactive than proactive (R5)", which also tend to be common among SMEs. As reported by Akhtar et al. (2014) the Internet has the capability to generate future growth for SMEs.

Johnson \& Scholes (1997) believe that SMEs can usually not afford complex market analysis and studies from bigger consultancy companies. Therefore, strategic decision-making is often based on intuition, experience or just guessing (Welter, 2003). This is in line with a statement of one participant (R5): “It wasn't a lot of market analysis (...) it is a lot of actively looking for new suppliers and partners. (...) Exhibitions are very important for us (...) this is where all the suppliers and all the other agents are."

In general, all respondents admit that it is really difficult to find the right partner or even a company to acquire- "I don't think it is that easy to go and find a strategic partner without really knowing who they are (R5)."

\subsection{Future Growth of the Firm}

In order to identify the most suitable growth strategy, the participants were asked to explain the skills and resources needed to grow, the problems for the company to grow, the current process of finding acquisition targets, and to define the characteristics of the company they are looking for.

\subsubsection{Skills and Resources}

In terms of skills and resources needed to grow in the future, all participants mention the terms "HR", "Relationships", "Suppliers", "Knowledge" and "Finance". Whereas one participant (R1) highlights the importance of knowledge and relationships by saying, "I guess it is the knowledge of the industry (...) it is all about building up relationships with your manufacturers and suppliers." Another respondent (R2) expresses the importance of Finance and HR: "Finance is obviously important (...) but you also need to have a good sales force. HR is an important factor for any business to grow." This is in line with Penrose (1959, cited in Pasanen, 2007) who argued that the availability and quality of managerial resources are a key constraint of firm growth. But also the importance of suppliers for chemical distributors was mentioned: “(...) I would say suppliers are extremely important (...) we need suppliers that have got registered products (R5)."

According to all interviewees, access to finance is not a problem: "I think we have the resources to grow organically and inorganically (R4)." Two other participants (R3; R5) confirm this by saying, "Yes we have the resources to grow inorganically, as we have full support by the board of directors" and "Inorganically, we definitely have. Our owner has actually released money for us to buy a company”.

As stated earlier, inorganic growth has numerous advantages for SMEs (Hyland et al., 2013; 
McKaskill, 2010). However, there are certain skills and resources needed to grow. The role of the owner/manager was discussed in the earlier chapters. In this case study, the owner/manager cannot be seen as a limiting growth factor as he is willing to buy a new company. In the SME literature, access to finance is always seen as one of the biggest barriers to grow (Storey, 1994). But as seen in the previous paragraph, access to finance is also not a limiting growth factor.

\subsubsection{Growth Problems}

It is not easy for SMEs and in particular for the UK based distributor to find companies to buy: "If you don't have a formal contact within a company, it is extremely difficult (R3)." Other participants mention problems such as time and human resources: "It is difficult because you need the time to find acquisition targets (...) You need to have many [human] resources to grow inorganically, we don't have at the moment (R1)." Overall, the biggest problem still remains: "Finding the company with the right size, for sale and pretty much fits in with our business (R2)."

\subsubsection{Finding Acquisition Targets}

The distributor is looking for companies for many years now. One interviewee (R5) describes the situation as follows: "We tried it on our own (...) word of mouth (...) but we found absolutely nothing." On top of that, there is no checklist or any kind of process in place to find acquisition targets. So far, looking for a company was quite informal and more a matter of luck, as one interviewee (R3) points out, "(...) on the other hand it can also be quite informal. You just meet up for lunch and ask them if they want to sell or not”. Nevertheless, the company realised that without any process and/or checklist in place they are going nowhere. That's why they recently contacted a consultancy company, who is looking for possible acquisition targets.

\subsubsection{Characteristics of the Target Company}

The characteristics of the target company are described clearly: "We want to find a company, which is smaller than ours; up to 5 million (...) predominantly working in the UK (...) we are also looking for an overlap in the products and the markets (R5)." Other respondents also mention characteristics such as "similar product portfolio", "strategic fit" and "UK based company".

According to Pearson (1989, p. 42), and as already mentioned earlier by a respondent, the problem for smaller businesses is to make a suitable person available without regular work suffering. Looking for acquisitions takes time, which SMEs normally don't have. Using outside help is one possibility of finding acquisition candidates and may be helpful and cost-effective. There are several sources of help available such as merchant banks, business brokers, and accounting firms or as in this case: specialist advisers. The overall goal of the consultancy company is to research the market and ideally identify possible acquisition candidates. On behalf of the client, they then approach short-listed candidates.

Moreover, the work of the consultancy firm is usually undertaken for a fee. The advantage of 
using outside help is that "the day-to-day management of the existing business does not suffer by diverting executive effort into acquisition search" (Pearson, 1989, p. 43). On top of that, consultancy firms usually have an existing network of contacts within the industry and also amongst other consultancy companies (Pearson, 1989).

\subsubsection{Employee Recommendations}

In line with the aims of this study, the participants were asked to evaluate the most suitable future growth strategy for the company.

For the majority of the participants, the most suitable growth strategy is a mix of organic and inorganic growth. "It is a combination of organic and inorganic growth. The economy seems to be improving except in Greece (...) again SMEs are not looking to make an acquisition every year. The last one we made was in 2006 (R3)." Another interviewee (R1) explains the importance of inorganic growth due to the amount of regulations, "Acquisitions and setting up Strategic Alliances, is more important than ever before (...) as a result of REACH."

Furthermore, finding the right balance between those options is very important. The ideal way to move forward for one participant (R5) is " (...) a combination of both or actually three things. It is trying to find a new company to give us a boost, it is also trying to do organic growth as we do in certain areas, but also working through partners, alliances and agents (...)". It is clear to see that every participant supports inorganic growth, in form of an acquisition, as the next step to grow: "For us, I think the main way we are going to grow is by acquisition, 100\%! (R2)." Another interviewee (R5) states that, "for a small business adding 5 million up to the business is very difficult to do organically."

This is in line with the earlier stated report of the BCG about speciality chemical distribution, which states that Chemical distributors are "expected to continue targeting inorganic growth to build out their product portfolios and extend their regional coverage" (Jung et al., 2014). Another industry report by Chemagility (2008) supports this by claiming that small speciality distributors tend to buy other small speciality companies and further expand their niche operations geographically.

In general, every respondent emphasises the need of organic and inorganic growth for small businesses to survive. "I think you need a combination of both. I think organic growth would be a lot extending and expanding your customers. And inorganic is really good for adding something up (R5)."

Jung et al. (2014) point out that the combination of organic and inorganic growth as well as maintaining a strong relationship with the suppliers is a big opportunity in a highly fragmented chemical distribution market. Moreover, it is very important to provide value to suppliers through deep knowledge of products, applications, and local markets (Jung et al., 2014). Figure 3 summarizes the main findings of the case study. 


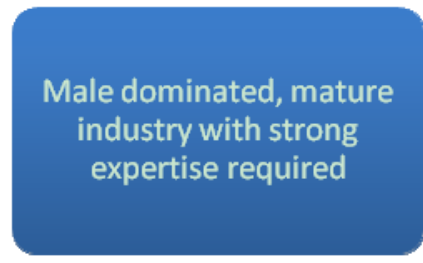

Highly fragmented

industry with strong

presence of consolidation

and regulatory

compliance
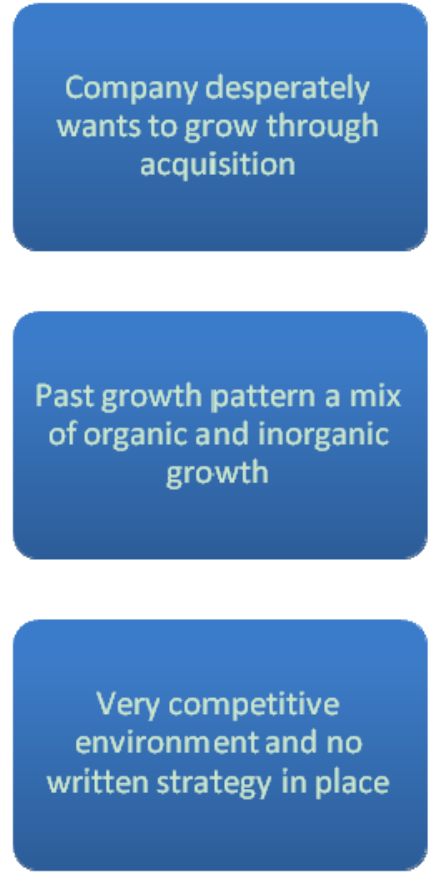

Figure 3. Main findings
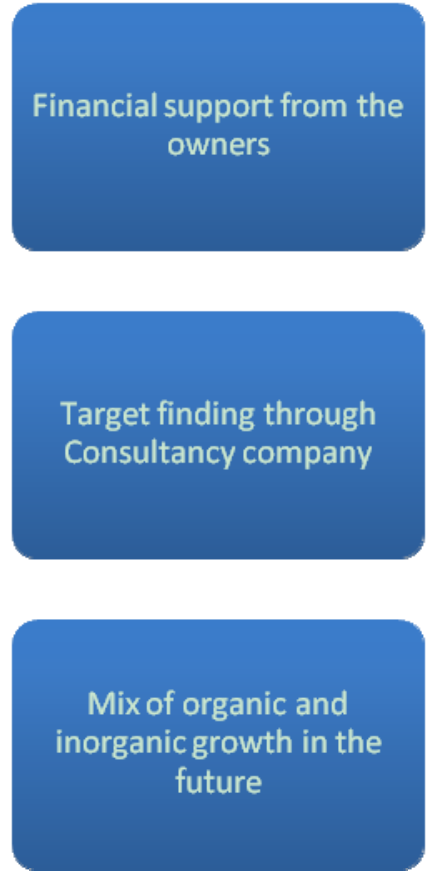

Many challenges within

the industry (e.g.

Regulations,

Consolidation)

\section{Conclusion}

This research paper has shown that SMEs play an essential role in the overall economy and especially in the UK chemical distribution industry (CIA, 2015). Due to the fact that the chemical industry is heavily understudied and there is no research available that combines SME growth strategies and the chemical distribution industry the aim of this study was to evaluate the different growth strategies of a UK small medium-sized chemical distributor.

Based on secondary research, the main growth strategies for SMEs could be categorised in organic and inorganic growth. Through semi-structured interviews, both types of growth could be confirmed. The current growth strategy is a mix of organic and inorganic growth, which is typical among SMEs in the chemical distribution industry. Over the last years, the UK chemical distributor increased the product portfolio and customer base through a number of strategic alliances.

As the UK chemical distribution industry is highly fragmented and characterised by regulatory compliance and consolidation, the current growth strategy seems to be ideal to survive in such a fierce business environment. The analysis of primary data has shown that the only factor preventing the firm to grow is Human Resources: employees don't have the time to look actively for an acquisition target, as they are too busy with the work they are doing on a daily basis.

However, the company realises the limiting factor and outsourced the target finding process to an external consultancy company. This is common among SMEs, as identifying acquisition targets, which are in line with the corporate strategy of the firm, is the biggest challenge for 
SMEs who are willing to grow inorganically (Pearson, 1989). The findings of this study can support the statement of several scholars such as Delmar et al. (2003), Farouk et al. (2011), Gibb \& Davis (1990) and Pasanen (2007), who argue that the growth pattern changes by firm characteristics. As already mentioned, the owner/manager and access to finance cannot be seen as growth barriers of the company. However, this might be completely different in other SMEs.

To conclude this study, recommendations are as follows:

Firstly, the best way to move forward for the company and in line with several industry reports as well as the primary data is a mix of organic and inorganic growth in the future. To make sure the company remains successful an acquisition is the next step for the company to grow. This prevents the company from being bought by a competitor. Due to the fact that especially smaller companies cannot afford an acquisition every year, growing organically is very important as well and should not be underestimated.

Secondly, the company is on the right path and should remain their operations as they are. However, the company could further improve in communicating a clear strategy to its employees and in formulating short-term as well as long-term strategic plans. The diversification strategy seems to be ideal in the chemical distribution industry.

Finally, the company should further focus on their strengths such as service, know-how, technical support and building personal relationships. Due to the fact that REACH is going to change the whole industry in 2018 , it is very important to find principals, who have already registered their products.

In the future, it will also be important to diversify the supplier base in order to be less reliant on one or two major principals. Furthermore, the company should focus on the existing product groups and look for other opportunities to grow. A mix of organic and inorganic growth will be the key to be successful in the future.

\section{References}

Akhtar, N., Azeem, S. M., \& Mir, G. M. (2014). Strategic Role of Internet in SMES Growth Strategies. International Journal of Business Management and Economic Research, 5(2), 20-27.

AT Kearney. (2014). Chemicals Executive M\&A Report 2014. AT Kearney. [Online] Available: http://www.atkearney.co.uk/chemicals/chemicals-executive-m-a-report-2014

Bartlett, C., Beamish, P., \& Ghoshal, S. (2008). Transnational Management. New York: McGraw-Hill

BIS. (2014). SMEs key enablers of business success. GOV.UK. [Online] Available: https://www.gov.uk/government/publications/smes-enablers-of-success-and-economic-rationa le-for-government-intervention 
Brouthers, K. D., Brouthers, L. E., \& Wilkinson, T. J. (1995). Strategic alliances: Choose your partners. Long $\quad$ Range 2-25. http://dx.doi.org/10.1016/0024-6301(95)00008-7

Brouthers, K. D., Van Hastenburg, P., \& Van Den Ven, J. (1998). If most mergers fail why are they so popular? International Journal of Strategic Management: Long Range Planning, 31(3), 347-353. http://dx.doi.org/10.1016/s0024-6301(98)80002-2

Bryman, A., \& Bell, E. (2011). Business Research Methods (3rd ed.). New York: Oxford

Caiazza, R., \& Volpe, T. (2015). M\&A process: a literature review and research agenda. Business Process Management Journal, 21(1), 205-220. http://dx.doi.org/10.1108/BPMJ-11-2013-0145

Carter, S., \& Jones-Evans, D. (2000). Enterprise and Small Business-Principles, Practice and Policy. Essex: Pearson Education Limited

CBA. (2015). CBA Supply Chain Trends March 2015. [Online] Available: http://www.chemical.org.uk/news/cbanews/cbasupplychaintrendsmarch2015.aspx

Chang, J., \& Beacham, W. (2014). M\&A a key facet of growth. ICIS Chemical Business, (July), pp.1-5.

Chapman, K., \& Edmond, H. (1998). Mergers/Acquisitions and Restructuring in the EU Chemical Industry: Patterns and Implications. Regional Studies, 34(8).

Chemagility. (2008). The UK Chemical Distribution Market Report 2008.

Chemagility. (2012). A Global Perspective on the World Chemical Distribution Market, First Panel Session: Chemical Distribution Industry Landscape, FECC Annual Congress, Lisbon, May 21-23, 2012. [Online] Available: http://www.assicconline.it/menu/documents/06_brown.pdf

Chemweek. (2012). Distribution-Robust Despite Market Uncertainty. IHS Chemical Week, 7(14), 21-27.

CIA. (2015). Chemical Industry Association. CIA. [Online] Available: http://www.cia.org.uk/AboutUs/AboutCIA.aspx

Cohen, D., \& Crabtree, B. (2006). Qualitative Research Guidelines Project. Robert Wood Johnson Foundation. [Online] Available: http://www.qualres.org/HomeSemi-3629.html

Delmar, F., Davidsson, P., \& Gartner, W. B. (2003). Arriving at the high-growth firm. Journal of Business Venturing, 18, 189-216. http://dx.doi.org/10.1016/S0883-9026(02)00080-0

Districonsult. (2012). Chemical Distribution in 2012. Districonsult. [Online] Available: https://www.associquim.org.br/ebdquim2012/palestras/Ebdquim2012 GüentherEberhard.pdf

Districonsult. (2013). Old Game-New Rules? Chemical Distribution in the Age of Volatility. [Online]

Available: 
http://www.districonsult.com/en/index-districonsult\%2Bnewsletter-1-34\%2B \%2Bold\%2Bg ame\%2Bnew\%2Brules\%2B2013.html.

EC. (2015). What is a SME? European Commission. [Online] Available: http://ec.europa.eu/enterprise/policies/sme/facts-figures-analysis/sme-definition/index_en.ht $\mathrm{m}$

ECB. (2000). Mergers and Acquisitions involving the EU Banking industry-Facts and Implications. European Central Bank. [Online] Available: www.ecb.int/pub/pdf/other/eubkmergersen.pdf

Elmuti, D., \& Kathawala, Y. (2001). An overview of strategic alliances. Management Decision, 39, 205-218. http://dx.doi.org/10.1108/EUM0000000005452

EWCS. (2014). Chemical Industry: Working conditions and job quality. Eurofound. [Online] Available:

http://www.eurofound.europa.eu/publications/information-sheet/2014/working-conditions/ch emical-industry-working-conditions-and-job-quality

Falter, W. (2015). Size does matter in chemical distribution. Journal of Business Chemistry, 12(2), 55-65.

Farouk, A., \& Saleh, M. (2011). An Explanatory Framework for the Growth of SMEs A System Dynamic Approach. Proceedings of the 29th International Conference of the System Dynamics Society.

Faulkner, D., Teerikangas S., \& Joseph R. J. (2012). The Handbook of Mergers and Acquisitions. Oxford: Oxford University Press. http://dx.doi.org/10.1093/acprof:oso/9780199601462.001.0001

FECC. (2013). The Chemical distribution Sector in Europe. [Online] Available: http://www.fecc.org/fecc/about-fecc/the-chemical-distribution-sector-in-europe

FECC. (2015). European business plan 2015. [Online] Available: http://www.fecc.org/fecc/images/stories/downloads/GTDP/2014/FECC_BusPlan_2015_def.p $\mathrm{df}$

Fermont, M. (2007). Channel Management in the Chemical Industry - Selecting the Right Option. Journal of Business Chemistry, 4(3).

Fielden, S. L., Davidson, M. J., \& Makin, P. J. (2000). Barriers Encountered During Micro and Small Business Start-up in North-West England. Journal of Small Business and Enterprise Development, 7, 295-304. http://dx.doi.org/10.1108/EUM0000000006852

Frost, L. (2013). Distribution: Capturing Growth Opportunities. IHS Chemical Week. [Online] Available:

http://www.chemweek.com/lab/Distribution-Capturing-growth-opportunities_56556.html

FSB. (2015). Small Business Statistics. Federation of Small Businesses. [Online] Available: http://www.fsb.org.uk/stats 
Fullsurge. (2013). Strategic Business Growth. Slideshare. [Online] Available: http://de.slideshare.net/NancyWulz/uni-strategic-business-growthday-1-201309?related=1

Gibb, A., \& Davies, L. (1990). In pursuit of frameworks for the development of growth models of the small business. International Small Business Journal, 9(1), 15-31. Cited in: Farouk, A., \& Saleh, M. (2011). An Explanatory Framework for the Growth of SMEs A System Dynamic Approach. Proceedings of the 29th International Conference of the System Dynamics Society.

Gibson, B., \& Cassar G. (2005). Longitudinal Analysis of Relationships Between Planning and Performance in Small Firms. Small Business Economics, 25, 207-222. http://dx.doi.org/10.1007/s11187-003-6458-4

Global Chemicals. (2015). Chemicals Industry Profile: Global (pp. 1-32). Business Source Premier, EBSCO host, viewed 07 March 2015.

Growth Business. (2015). One in three SMEs to busy to formulate Growth Strategy. Growth Business. [Online] Available: http://www.growthbusiness.co.uk/news-and-market-deals/business-news/2479577/one-in-thr ee-smes-too-busy-to-formulate-growth-strategy.thtml\#sthash.Nqqei7pA.dpuf

Heffernan, M. (2012). Why mergers fail. Moneywatch. [Online] Available: http://www.cbsnews.com/news/why-mergers-fail/

Hoang, T. V. N., \& Lapumnuaypon, K. (2007). Critical Success Factors in Merger \& Acquisition Projects. [Master Thesis]. Umea School of Business

Hoffmann, W. H., \& Schlosser, R. (2001). Success Factors of Strategic Alliances in Small and Medium-sized Enterprises-An Empirical Survey. Long Range Planning, 34, 357-381. http://dx.doi.org/10.1016/S0024-6301(01)00041-3

Hornke, M. (2012). Grosse-Hornke Private Consult: Study “Chemical Distribution 2012”. Münster: Hornke-Consult.

Hyland, B., Tilly, B., \& Glennon, R. (2013). Growth Strategies for SMEs. Enterprise-Ireland. [Online]

Available: http://www.enterprise-ireland.com/en/events/ourevents/finance-for-growth/growth-strategiesfor-smes.pdf

Johnson, G., \& Scholes, K. (1997). Exploring Corporate Strategy (4th ed.). London: Prentice Hall.

Johnston, K. (2015). Organic vs. Inorganic Growth Business. Smallbusiness. [Online] Available: http://smallbusiness.chron.com/organic-vs-inorganic-growth-business-37311.html

Jung, U. (2012). Chemical distribution-Global picture, trends and opportunities. ANIQ. [Online] Available: http://www.aniq.org.mx/foro/2012/pdf/7\%20QUINTA\%20SESION\%20PLENARIA/1.-Udo \%20Jung-Chemical\%20Distribution\%20-\%20ANIQ\%20Oct\%20\%202012\%20-Final.pdf 
Jung, U., Wolleswinkel, R., Hoffmann, C., \& Rothman, A. (2014). Specialty Chemical Distribution-Market Update. Boston Consulting Group.

Kalmbach, C., \& Roussel, R. (1999). Dispelling the myths of alliances. Cited in: Elmuti, D. \& Kathawala, Y. (2001). An overview of strategic alliances. Management Decision, 39, 205-218.

Kim, J., Haleblian, J., \& Finkelstein, S. (2011). When Firms Are Desperate to Grow via Acquisition: The Effect of Growth Patterns and Acquisition Experience on Acquisition Premiums. Administrative Science Quarterly, 56, 26-60. http://dx.doi.org/10.2189/asqu.2011.56.1.026

Lampadarios, E. (2016a). What future for SME distributors? Specialty Chemical Magazine, pp. 36-38. [Online] Available: www.specchemonline.com

Lampadarios, E. (2016b). Critical Success Factors for SMEs: An Empirical Study in the UK Chemical Distribution Industry. International Journal of Business and Management, 11(7), 67-82. http://dx.doi.org/10.5539/ijbm.v11n7p67

Lampadarios, E. (2016c). Critical challenges for SMEs in the UK chemical distribution industry. Journal of Business Chemistry, 13(1), 17-32.

Lockett, A., Wiklund, J., Davidsson, P., \& Girma, S. (2011). Organic and Acquisitive Growth: Re-examining, Testing and Extending Penrose's Growth Theory. Journal of Management Studies, 48, 48-74. http://dx.doi.org/10.1111/j.1467-6486.2009.00879.x

Machado, C. F. (2013). Effective Human Resources Management in Small and Medium Enterprises: Global Perspectives. IGI Global.

Mack, S. (2015). Organic Growth Strategy. Smallbusiness. [Online] Available: http://smallbusiness.chron.com/organic-growth-strategy-57130.html

Marshall, C., \& Rossmann, G. B. (2006). Designing Qualitative Research (4th ed.). Thousand Oaks, CA: Sage. Cited in: Saunders, M., Lewis, P., \& Thornhill, A. (2012b). Research Methods for Business Students. Harlow: Pearson.

Matlay, H. (1999). Employee relations in small firms: A micro business perspective. Employee Relations, 21(3), 196-285. Cited in Machado, C. F. (2013). Effective Human Resources Management in Small and Medium Enterprises: Global Perspectives. IGI Global.

McKaskill, T. (2010). Ultimate Acquisitions. Melbourne: Breakthrough Publications. [Online] Available: http://www.drexit.net/resources/McKaskill-Ultimate-Acquisitions.pdf

Mortelmans, S., \& Reniers, G. (2012). Practitioner's Section: Chemical distribution in Belgium from 2007 to 2010: An empirical study. Journal of Business Chemistry, 9(2).

O'Regan, N., \& Ghobadian, A. (2004). Re-visiting the Strategy-Performance Question: An Empirical Analysis. International Journal of Management and Decision Making, 5, 144-170. http://dx.doi.org/10.1504/IJMDM.2004.005346 
OECD. (2002). High-Growth SMEs and Employment. [Online] Available: http://www.oecd.org/cfe/smes/2493092.pdf

Papulova, E., \& Papulova, Z. (2006). Competitive Strategy and Competitive Advantages of small and midsized manufacturing enterprises in Slovakia. E-Leader, International leadership and networking conference, Slovakia.

Pasanen, M. (2007). SME GROWTH STRATEGIES: ORGANIC OR NON-ORGANIC? Journal of Enterprising Culture, 15, 317-338. http://dx.doi.org/10.1142/S0218495807000174

Pearson, B. (1989). Successful acquisition of unquoted companies (3rd ed.). Vermont: Gower Publishing Company.

Penrose, E. T. (1959). The Theory of the Growth of the Firm, 1, 1-23. New York: John Wiley \& Sons Inc.

Pleitner, H. J. (1986). StrategischesVerhaltenmittelständischerUnternehmen. Internationales Gewer bearchiv, 34, 159-171. Cited in Terziovski, M. (2007). Energizing Management through Innovation and Entrepreneurship: European Research and Practice (pp. 110-127). London: Routledge.

Porter, M. E. (1980). Competitive Strategy-Techniques for Analysing Industry and Competitors. New York: Free Press.

Roberts, A., Wallace, W., \& Moles, P. (2012). Mergers and Acquisitions. Edinburgh Business School 2015. [Online] Available: https:/www.ebsglobal.net/documents/course-tasters/english/pdf/h17mq-bk-taster.pdf

Robinson, R. B., \& Pearce, J. A. (1984). Research Thrusts in Small Firm Strategic Planning. Academy of Management, 9, 128-137. http://dx.doi.org/10.5465/amr.1984.4278109

Salvato, C., Lassini, U., \& Wiklund, J. (2007). Dynamics of external Growth in SMEs: A Process Model of acquisition capabilities emergence. Schmalenbach Business Review, 59(July), 282-306.

Saunders, M., \& Lewis, P. (2012a). Doing Research in Business and Management: An Essential Guide to Planning Your Project. Harlow: Financial Times Prentice Hall.

Saunders, M., Lewis, P., \& Thornhill, A. (2012b). Research Methods for Business Students. Harlow: Pearson.

Schell, C. (1992). The value of the Case Study as a research strategy. Manchester Business School.

Smallbone, D., Leigh, R., \& North, D. (1995). The characteristics and strategies of high growth SMEs. International Journal of Entrepreneurial Behaviour \& Research, 1(3). http://dx.doi.org/10.1108/13552559510100657

Storey, D. J. (1994). Understanding the small business sector. London: International Thomson Business Press. 


\section{Macrothink}

Case Studies in Business and Management

ISSN 2333-3324

2016, Vol. 3, No. 2

Swoboda, B., Meierer, M., Foscht, T., \& Morschett, D. (2011). International SME Alliances: The Impact of Alliance Building and Configurational Fit on Success. Long Range Planning, 44, 271-288. http://dx.doi.org/10.1016/j.1rp.2011.04.002

Terziovski, M. (2007). Energizing Management through Innovation and Entrepreneurship: European Research and Practice (pp. 110-127). London: Routledge.

Todeva, E., \& Knoke, D. (2005). Strategic alliances \& models of collaboration. Management Decision, 43(1), 123-148. http://dx.doi.org/10.1108/00251740510572533

Tonge, J. (2001). A Review of Small Business Literature Part 2: Birth, Growth and Death of The Small Business. Manchester Metropolitan University Business School Working Paper Series (pp. 1-28).

Varaiya, N. P., \& Ferris, F. R. (1987). Overpaying in corporate take-overs: The winner's curse. Financial Analysts Journal, 43, 64-70. http://dx.doi.org/10.2469/faj.v43.n3.64

Walberer, A. (2014). Positive outlook for chemicals M\&A. ICIS Chemical Business, (April).

Wang, C., Walker, E., \& Redmond, J. (2007). Explaining the Lack of Strategic Planning in SMEs: The Importance of Owner Motivation. International Journal of Organisational Behaviour, 12, 1-16.

Welter, F. (2003). Strategien, KMU und Umfeld-Handlungsmuster und Strategiegenese in kleinen und mittleren Unternehmen. Berlin: Duncker \& Humblot. http://dx.doi.org/10.3790/978-3-428-51326-0

Young, P. (2014). Positive M\&A to continue in 2014. ICIS Chemical Business, (February), $1-6$.

\section{Copyright Disclaimer}

Copyright for this article is retained by the author(s), with first publication rights granted to the journal.

This is an open-access article distributed under the terms and conditions of the Creative Commons Attribution license (http://creativecommons.org/licenses/by/3.0/). 